Brit. J. industr. Med., 1948, 5, 70.

\title{
FIBROṠIS IN THE LUNGS OF A SILVER FINISHER
}

\author{
BY \\ H. E. HARDING \\ From the Department of Pathology, Sheffield University \\ (RECEIVED FOR PUBLICATION, JANUARY 28, 1948)
}

McLaughlin, Barrie, Grout, and Harding (1945) and Barrie and Harding (1947) have reported on the lungs of several silver finishers, in which quite heavy loading with iron oxide has not been accompanied by any fibrosis. There is also evidence (Harding, 1945 ; Harding, Grout, and Lloyd Davies, 1947) that the forms of iron oxide used in the finishing of silver and silver-plated articles do not produce fibrosis in the lungs of experimental animals. It seems, therefore, important to record the following case in which the lungs show definite, though slight, fibrosis of a "reticulation" type. (The methods used by silver finishers have been described by McLaughlin and others, 1945.)

\section{Case Report}

A man aged 63 years had spent all his working life as a silver finisher except for five years during the 1939-45 war when he was a labourer with the English Steel Corporation. During these five years he was employed solely in the fitting shop and never worked in the fettling department. He died suddenly from coronary thrombosis supervening on coronary atherosclerosis : there was a large fibrous area in the anterior wall of his left ventricle indicative of previous coronary occlusion.

The lungs, examined after fixation in formol-saline, showed fibrous thickening of the pleura over the whole left lung : over the right lung the pleura was blue-black with a few small denser grey spots. Both lungs showed a fairly marked general fine emphysema together with a few bullæ at the anterior margins. They were fairly uniformly reddish-brown, and contained no nodules visible to the naked eye. The hilar glands were slightly . enlarged and reddish brown.

Microscopically the lungs resembled those of other silver finishers, but there were also small areas of fibrosis of the "reticulation" type with longitudinal or radial collagen fibres (figs. 1 to 4). There was much pigment in the sections, in and around the areas of fibrosis as well as within some of the alveoli and in perivascular aggregates that showed no fibrosis. Incinerated sections showed that most of the pigment was iron, with silver deposited on elastic laminæ : the amount of silica seen in polarized light was small, and appeared no more than in normal controls.

Chemical examination of the lungs showed that ash constituted 8.38 per cent., iron (as $\mathrm{Fe}_{2} \mathrm{O}_{8}$ ) 3.50 per cent., total silica 0.22 per cent., free silica nil, silver (as metal) 0.036 per cent. of the dry weight.

\section{Discussion}

There are many causes other than inhaled dust for fibrosis of the lung, and there is a general tendency for particulate matter to be held in places where fibrous tissue is being formed. No evidence has been found that this man had any unusual exposure to silica, and the chemical and microscopical examinations of his lungs do not show more than may be accounted "normal" quantities of this substance. The histological character of the fibrosis, however, resembles that in the early stage of pneumoconiosis, and, in the absence of definite evidence of some other ætiology, one must seriously consider the fibrosis as due to dust. Silver polishers are exposed to a variety of dusts (iron oxide, alumina, metallic silver), none of which is believed to be harmful in the quantities commonly inhaled in this industry. The rouge used in polishing varies a little in its composition, and it is possible that at some period during his long employment he may have been exposed to some harmful ingredient in the polishing powder. Unfortunately the firm has recently gone out of business, and it is not possible to enquire into any unusual risk. The very large amount of iron found in the lungs probably reflects the fact that this man was working as a silver finisher up to the time of his death.

The present case suggests that it may for the moment be wise not to accept these dusts as invariably and completely harmless. The verygreat individual variation in susceptibility to the harmful action of inhaled silica may well be 


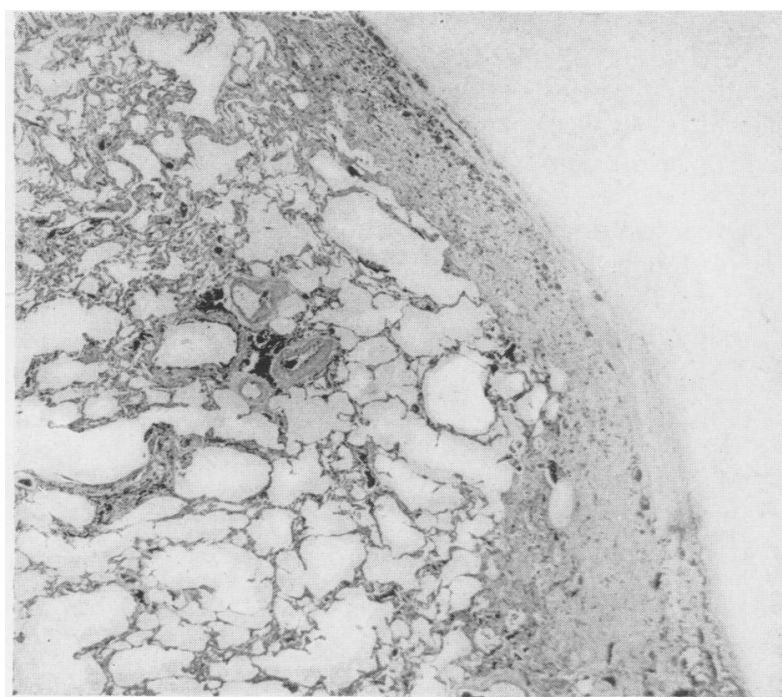

FIG. 1.-Subpleural fibrosis. Hæmatoxylin and eosin $\times 14$.

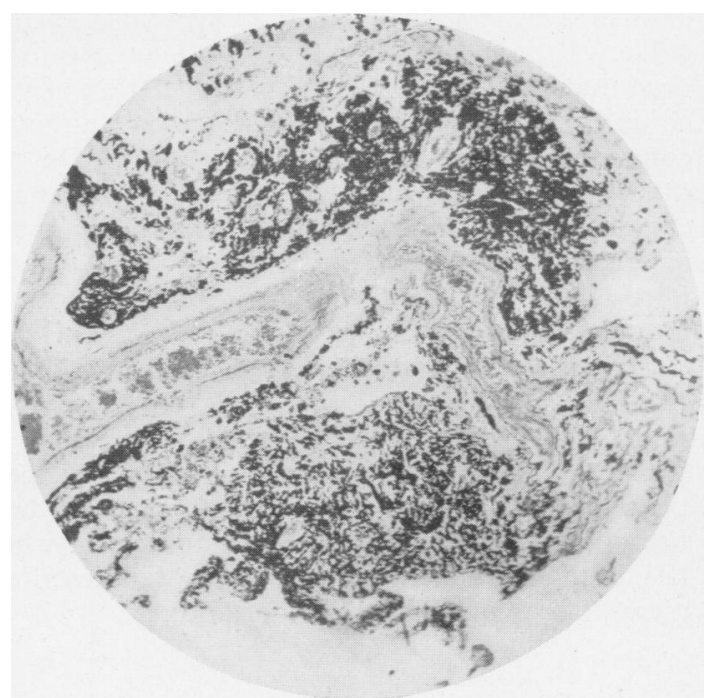

FIG. 2.-Periarterial fibrosis. Hæmatoxylin and eosin $\times 54$. The staining of elastica is due to silver impregnation.

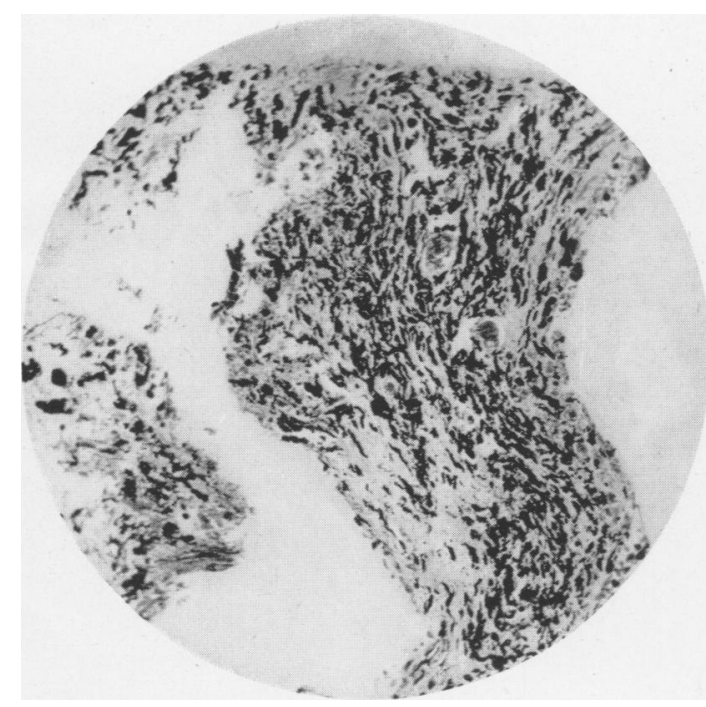

Fig. 3.-Linear fibrosis. Hæmatoxylin and eosin $\times 54$. Nearly all the pigment is iron oxide.

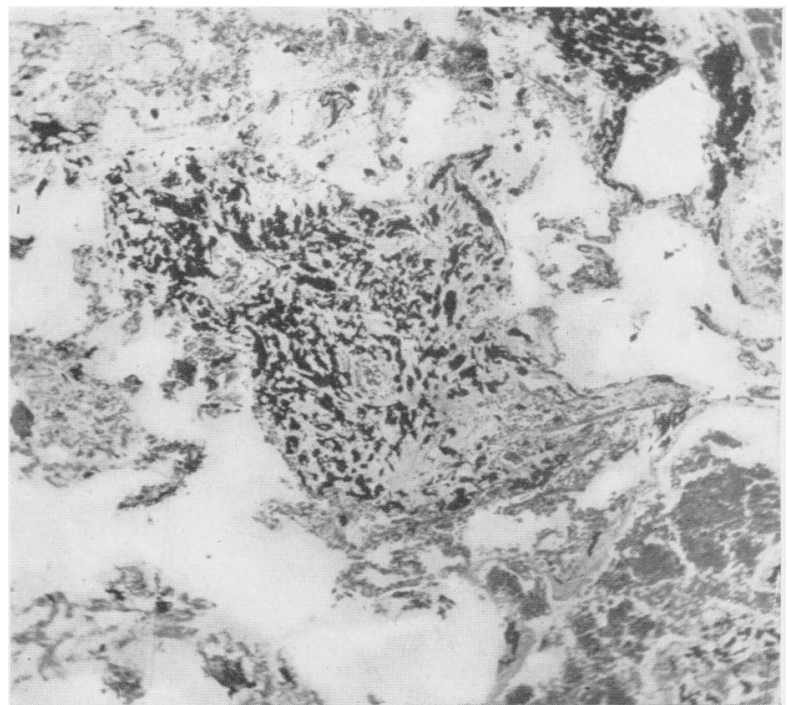

FIG. 4.-Radial fibrosis. Hæmatoxylin and eosin $\times 75$. 
paralleled by a similar varied susceptibility to iron oxide. It seems possible that this man may have been unusually reactive, and that inhalation of iron oxide has resulted in fibrosis in his case although commonly it produces no such effect. On the other hand, even a wide experience of the histological characters of pneumoconiosis does not allow one to assert with complete confidence that the type of fibrosis found here is solely and necessarily caused by dust.

The amount of fibrosis in these lungs was small ; the fibrotic areas were found only on microscopic examination and were fairly widely separated. It seems unlikely that the fibrosis per se could have been responsible for any disability that could have been detected during life. The emphysema, which has been noted in all the cases so far described, seems of greater clinical importance.

\section{Summary}

The lungs of a man, aged 63 years, who had spent all his working life as a silver finisher, show scattered microscopic fibrosis of the " reticulation" type with linear and radial collagenous fibrosis. He had had no unusual exposure to silica, and his lungs did not contain an abnormal amount of this substance. It is suggested that he may have been unusually sensitive to the presence of inhaled iron oxide, which is commonly inert.

I am indebted to Dr. G. Forbes for the specimen and for the autopsy notes, and to Dr. G. B. Oliver, H.M. Medical Inspector of Factories, for the working history. The photomicrographs were taken by Mr. A. W. Collins, F.I.M.L.T.

\section{REFERENCES :}

Barrie, H. J., and Harding, H. E. (1947). Brit. J. industr. Med., 4, 225. Harding, H. E. (1945). Ibid., 2, 32.

Harding, H. E., Grout, J. L. A., and Lloyd Davies, T. A. (1947) Ibid., 4, 223 .

McLaughlin, A. I. G., Barrie, H. J., Grout, J. L. A., and Harding, H. E. (1945). Lancet, 1, 337. 